\title{
Development of the Optimal Wastewater Treatment Technologies Refining of Precious Metals
}

\author{
Liudmila V. Biketova, \\ Iurii N. Lisakov* and Sergei D. Ershov \\ Gipronickel Institute \\ 11 Grazhdansky ave., St. Petersburg, 195220, Russia
}

Received 22.03.2016, received in revised form 14.05.2016, accepted 06.07.2016

The most widespread method in gold production is cyanide leaching of ore concentrates.

Most of gold ore deposits in the Russian Federation are located in the Far North and Far East with their climate zone characterized by a positive water balance. In this regard, there arises a need to solve the problem of wastewater treatment.

The process of cyanide removal is well known and proven in an industrial scale. The presence of nonferrous metal sulfides and iron in ore concentrates leads to an increased consumption of cyanides caused by thiocyanate production. As a result, gold mining companies have to solve the problem of neutralization of discharged water both in terms of cyanide and thiocyanates. The problem is currently particularly burning at Russia's operations as requirements for cyanide and thiocyanate contents in treated effluents are virtually commensurate.

This present paper summarizes the results of research in the field of treatment of wastewater containing, along with cyanides, a significant amount of thiocyanates.

Our studies have shown high efficiency of the process of wastewater oxidation by ozone.

It has been shown that the ozone oxidation process runs at high rate and is accompanied by cyanide regeneration.

This saves more than fifty percent on the cost of ozone production, the latter being a major economic limiting factor for the application of this technology.

The ozonation technology ensures the absence of secondary contamination by reagents and treated effluent intermediates.

The developed method provides the compliance with the legislation requirements on the content of cyanides and thiocyanates in wastewater. Lower cost of the process resulted from the lack of reagents, and hence, cost of their purchase and delivery to gold mining operations, and a potential for cyanide regeneration make a proposed method very attractive.

Keywords: cyanides, thiocyanates, waste water, reverse osmosis, autoclave oxidation, ozonation.

Citation: Biketova L.V., Lisakov Iu.N., Ershov S.D. Development of the optimal wastewater treatment technologies refining of precious metals, J. Sib. Fed. Univ. Eng. technol., 2016, 9(5), 703-713. DOI: 10.17516/1999-494X-2016-9-5-703-713.

(C) Siberian Federal University. All rights reserved

* Corresponding author E-mail address: jnlis@nickel.ru 


\title{
Разработка оптимальной технологии очистки сточных вод рафинировочного производства драгоценных металлов
}

\author{
Л.В. Бикетова, Ю.Н. Лисаков, С.Д. Ершов \\ ООО «Институт Гипроникель» \\ Россия, 195220, Санкт-Петербург, Гражданский пр., 11
}

$\overline{П р и ~ п р о и з в о д с т в е ~ з о л о т а ~ н а и б о л е е ~ ш и р о к о е ~ р а с п р о с т р а н е н и е ~ и м е е т ~ м е т о д ~ ц и и н и р о в а н и я ~}$ рудных кониентратов.

Большинство месторождений золотосодержащих руд Российской Федеращии находится в районах Крайнего Севера и Дальнего Востока, климатическая зона которых характеризуется положительным водным балансом. В связи с этим возникает необходимость решения проблемы очистки сточных вод.

Технология очистки от цианидов хорошо известна и отработана в промышленном масштабе. Наличие в рудных концентратах сульфидов иветных металлов и железа влечет за собой увеличение расхода цианидов, связанного с образованием роданидов. Это приводит к тому, что золотодобывающие предприятия должны решать проблему обезвреживания сбрасываемых вод как от иианидов, так и от роданидов. Эта проблема в настоящее время особенно актуальна для предприятий Российской Федераџии, так как требования к содержанию роданидов и иианидов в очищенных стоках практически соизмеримы.

Данная работа обобщает результаты исследований в области очистки сточных вод, содержащих помимо цианидов значительное количество роданидов. Проведенные нами исследования показали высокую эффективность применения технологии окисления сточных вод озоном. Было продемонстрировано, что процесс окисления озоном идет с высокой скоростью и сопровождается проиессом регенераиии иианидов. Этот фактор приводит $\kappa$ тому, что затраты на получение озона, которые являются основным экономическим сдерживающим фактором для применения данной технологии, снижаются более чем в 2 раза. Технология озонирования обеспечивает отсутствие вторичного загрязнения реагентами и полупродуктами очищенных стоков.

Разработанный метод обеспечивает достижение требований законодательства по содержанию ичианидов и роданидов в сточных водах. Более низкая себестоимость процесса, связанная с отсутствием реагентов, соответственно, затрат на их приобретение $и$ доставку к золотодобывающим предприятиям, и возможность регенерачии ичианида делают предложенный метод весьма привлекательным.

Ключевые слова: цианиды, роданиды, сточные воды, обратный осмос, автоклавное окисление, озонирование.

\section{Введение}

Защита окружающей среды от техногенного воздействия является обязательной для действующих предприятий, а развитие и использование наиболее эффективных природоохранных решений актуальны как в научном, так и в практическом плане. Важное значение имеют экономические показатели применяемых природоохранных технологий.

Очевидно, что оптимальный вариант для предприятия - эксплуатация минимально затратного процесса детоксикации загрязнений, обеспечивающего требования законодательных документов к качеству воды. 
В настоящее время целый ряд отраслей промышленности применяет в своих технологических процессах соли синильной кислоты, химические свойства которых и определяют структуру их применения.

Цианиды широко используются в современной промышленности, но, пожалуй, наиболее известно их применение для извлечения золота и серебра из руд методом цианирования (один из процессов гидрометаллургии, основанный на растворении металла в цианистых растворах вследствие образования комплексных солей).

Также цианиды используются в химической, резинотехнической, лакокрасочной и инструментальной промышленностях, в процессах гальванотехники и металлообработки. В отходящих газах доменного производства содержатся цианистые соединения, которые переходят в водную фазу после мокрой очистки газов.

Объем производства и химический состав сточных вод различных производств определяют технологию их очистки до требуемых параметров.

\section{Международная классификация цианидов}

Цианиды в комплексных соединениях с металлами по величинам констант диссоциации классифицируются так:

- WAD (Weak Acid Dissociable - диссоциирующие слабокислотные). WAD включают в себя цианидные соединения, которые при рН 4.5 разрушаются с образованием $\mathrm{HCN}$ (aq) и CN-; к ним относятся цианидные комплексы $\mathrm{Cu}, \mathrm{Cd}, \mathrm{Ni}, \mathrm{Zn}, \mathrm{Ag}$, тиоцитанаты и другие комплексы с низкими константами диссоциации;

- SAD (Strong Acid Dissociable - диссоциирующие сильнокислотные). Относительно нетоксичными примерами SAD являются комплексы цианида с кобальтом, золотом и железом.

Цианиды, предназначенные для переработки, подразделяются на три класса:

- общие цианиды;

- WAD-цианиды;

- свободные цианиды.

Для конкретного раствора концентрация общих цианидов всегда больше или равна концентрации WAD-цианидов.

Концентрация WAD-цианидов всегда больше или равна концентрациям свободных цианидов. WAD содержат токсикологически и экологически важные формы цианидов, включая свободные цианиды и средне и слабо закомплексованные с металлами цианиды.

Общие цианиды включают в себя WAD-цианиды плюс относительно нетоксичные железоцианидные комплексы.

\section{Стабильность цианистых комплексов}

Стабильность цианистых комплексов наряду с их концентрацией в растворах является критерием, определяющим метод их разложения. Значения констант диссоциации цианидных комплексов и классификация цианистых соединений по их относительной стабильности в воде приведены в табл. 1 и 2 соответственно [1].

В результате взаимодействия простых водорастворимых цианидов с компонентами твердой и жидкой фаз пульпы образуются и другие цианистые соединения: простые нераствори- 
Таблица 1. Значения констант диссоциации $\left(K_{\partial и c}\right)$ цианидных комплексов

\begin{tabular}{|c|c|c|c|c|c|c|c|c|}
\hline$M e$ & $\mathrm{Zn}$ & $\mathrm{Cd}$ & $\mathrm{Ni}$ & $\mathrm{Cu}$ & $\mathrm{Fe}^{2+}$ & $\mathrm{Au}$ & $\mathrm{Ag}$ & $\mathrm{Fe}^{3+}$ \\
\hline$K_{\partial u c}$ & $10^{-16}$ & $10^{-19}$ & $10^{-21}$ & $10^{-29}$ & $10^{-35}$ & $10^{-38}$ & $10^{-41}$ & $10^{-42}$ \\
\hline
\end{tabular}

Таблица 2. Относительная стабильность цианистых соединений металлов в воде

\begin{tabular}{|l|l|}
\hline \multicolumn{1}{|c|}{ Тип соединения } & \multicolumn{1}{c|}{ Состав соединения } \\
\hline Свободный цианид & $\mathrm{CN}, \mathrm{HCN}$ \\
\hline Простые цианиды: & \\
\hline Легко растворимые & $\mathrm{NaCN}, \mathrm{KCN}, \mathrm{Ca}(\mathrm{CN})_{2}, \mathrm{Hg}(\mathrm{CN})_{2}$ \\
\hline Трудно растворимые & $\mathrm{Zn}(\mathrm{CN})_{2}, \mathrm{CuCN}, \mathrm{Ni}(\mathrm{CN})_{2}, \mathrm{Cd}(\mathrm{CN})_{2}, \mathrm{AgCN}$ \\
\hline «Слабые» комплексы металлов & $\mathrm{Zn}(\mathrm{CN})_{4}{ }^{2-}, \mathrm{Cd}(\mathrm{CN})_{3}{ }^{-}, \mathrm{Cd}(\mathrm{CN})_{4}{ }^{2-}$ \\
\hline Умеренно прочные комплексы металлов & $\mathrm{Cu}(\mathrm{CN})_{2}-, \mathrm{Cu}(\mathrm{CN})_{3}{ }^{2-}, \mathrm{Ni}(\mathrm{CN})_{4}{ }^{2-}, \mathrm{Ag}(\mathrm{CN})_{2}{ }^{-}$ \\
\hline Прочные комплексы металлов & $\mathrm{Fe}(\mathrm{CN})_{6}{ }^{3-}, \mathrm{Fe}(\mathrm{CN})_{6}{ }^{4-}, \mathrm{Co}(\mathrm{CN})_{6}{ }^{4-}, \mathrm{Au}(\mathrm{CN})_{2}{ }^{-}, \mathrm{Hg}(\mathrm{CN})_{4}{ }^{2-}$ \\
\hline
\end{tabular}

мые в воде, комплексные растворимые и нерастворимые цианиды. Простые нерастворимые цианиды $\left(\mathrm{CuCN}, \mathrm{Fe}(\mathrm{CN})_{2}\right.$ и др.) не токсичны, но в кислой среде они растворяются и переходят в простые токсичные цианиды. Группа комплексных водорастворимых цианидов включает как токсичные, так и нетоксичные соединения. К первым относятся цианиды меди и цинка, ко вторым - ферро- и феррицианиды $\left(\left[\mathrm{Fe}(\mathrm{CN})_{6}\right]^{3-}\right.$ и $\left.\left[\mathrm{Fe}(\mathrm{CN})_{6}\right]^{4-}\right)$. Нетоксичность ферро- и феррицианидов относительна, так как в определенных условиях эти соединения могут разлагаться с образованием простых водорастворимых цианидов.

Практически нерастворимым в воде нетоксичным комплексным цианидом является берлинская лазурь $\mathrm{Fe}_{4}\left[\mathrm{Fe}(\mathrm{CN})_{6}\right]_{3}$.

В стоках значительная часть цианидов обычно находится в форме простых солей $-\mathrm{NaCN}$, $\mathrm{KCN}, \mathrm{Ca}(\mathrm{CN})_{2}$, т.е. в форме реагентов, используемых при цианировании. Синильная кислота образуется в стоках в результате гидролиза солей или взаимодействия их с кислотами. Простые растворимые в воде цианиды нередко присутствуют и в смешанных стоках.

В цианистых и смешанных стоках при избытке простых водорастворимых цианидов медь и цинк входят в состав растворимых цианидов. С другой стороны, при избытке катионов этих металлов, что может быть в смешанных стоках, весь циан входит в состав нерастворимого простого цианида меди.

Роданиды - NaCNS, $\mathrm{Cu}(\mathrm{CNS})_{2}$ и др. - образуются в стоках в результате взаимодействия простых цианидов с сульфидами щелочных металлов и элементарной серой.

Сточные воды технологических процессов, в которых в качестве реагентов использовались соли синильной кислоты, как правило, содержат комплекс токсичных веществ: остаточных количеств вводимого реагента, продуктов реакции цианида с рудными минералами - цианидных комплексов металлов, а также роданидов. Следует отметить, что опасность цианидов зависит от конкретной формы их нахождения и концентрации. 


\section{Требования законодательных}

\section{и рекомендательных программных документов}

На присутствие указанных веществ в природных средах в России установлены экологические ограничения (предельно допустимые концентрации - ПДК), по требовательности не уступающие мировым экологическим нормативам, а в ряде случаев и превосходящие их. Так, предельная концентрация синильной кислоты в воздухе рабочей зоны не должна превышать

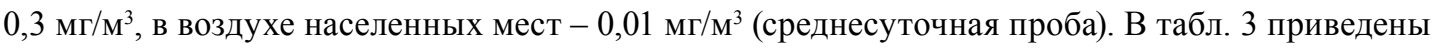
требования законодательства Российской Федерации к качеству воды.

Интенсивное развитие в XX в. горно-рудной, нефтяной, химической, фармацевтической, автомобильной и других отраслей промышленности, высокая концентрация промышленных объектов в Европе, Северной Америке и Японии привели к экологическому коллапсу. Государственная политика этих стран, а также внимание общественности к экологической проблеме позволили за последние годы на базе крупномасштабных разноплановых исследований создать отрасль, специализирующуюся на разработке и производстве материалов, технологий и оборудования для очистки газовых выбросов и сточных вод.

Применение опасных химических веществ, в том числе цианидов, регулируется в международном сообществе как через законодательные нормативы, обязательные к применению, так и через добровольно применяемые методики и практики, в том числе «Международный кодекс использования цианидов (ICMC)».

В Европейском союзе применение опасных химических веществ регулируется так называемой Директивой Севесо II (Seveso II Directive). “Свободный цианид и любые соединения, способные выделять свободный цианид в растворе,” внесены также в Список I Директивы по подземным водам (Groundwater Directive), которая запрещает любые утечки/сбросы, способные привести к ухудшению качества подземных вод, как в настоящий момент, так и в будущем. В 2000 г. Директиву по подземным водам в основном заменила Рамочная директива по водной среде (Water Framework Directive).

Европейский Парламент и Совет Европы приняли Директиву 2006/21/EC (Directive 2006/21/EC) по управлению отходами добывающих отраслей промышленности. Статья 13 обязывает “понижать концентрацию слабокислотного диссоциирующего цианида в хвостохранилищах до минимально возможного уровня, используя наиболее эффективные технологии”; на всех рудниках, введенных эксплуатацию после 1 мая 2008 г., запрещается сбрасывать отходы,

Таблица 3. Требования законодательных документов РФ

\begin{tabular}{|l|c|c|}
\hline \multicolumn{1}{|c|}{ Законодательный документ } & Вещество & $\begin{array}{c}\text { Норматив ПДК, } \\
\text { не более, мг/дм }\end{array}$ \\
\hline $\begin{array}{l}\text { Приказ Федерального агентства по рыболовству от 18.01.2010 № 20 } \\
\text { “Об утверждении нормативов качества воды водных объектов } \\
\text { рыбохозяйственного значения....” }\end{array}$ & цианид & 0,05 \\
\cline { 2 - 3 } $\begin{array}{l}\text { Предельно допустимые концентрации (ПДК) химических веществ в } \\
\text { воде водных объектов хозяйственно-питьевого и культурно-бытового } \\
\text { водопользования. Гигиенические нормативы ГН 2.1.5.1315-03. Дата } \\
\text { введения: } 15 \text { июня 2003 г. }\end{array}$ & роданид-ион & 0,1 \\
\cline { 2 - 3 } & рианид & 0,035 \\
\hline
\end{tabular}

$$
-707-
$$


содержащие свыше 10 г/т слабокислотного диссоциирующего цианида; для рудников, построенных или получивших разрешение на строительство до этой даты, разрешены сбросы с содержанием не более 50 г/т слабокислотного диссоциирующего цианида вначале с понижением этого предела до 10 г/т к 2018 г.

В соответствии с требованиями Руководства по охране окружающей среды, здоровья и труда для горнодобывающей промышленности Международной Финансовой Корпорации общее содержание цианидов в сбрасываемых в поверхностные водотоки сточных водах не должно превышать 1 мг/дм³ , а содержание свободного цианида -0.1 мг/ дм³.

Согласно Статье 14, компании также должны предоставить финансовые гарантии для обеспечения очистки территории после закрытия рудника [2].

Государственная политика ряда европейских стран, Северной Америки и Японии, внимание общественности к экологической проблеме позволили за последние годы на базе крупномасштабных разноплановых исследований создать отрасль, специализирующуюся на разработке и производстве материалов, технологий и оборудования для очистки газовых выбросов и сточных вод. Очистка сточных вод проводится с целью устранения вредных и опасных свойств, которые могут привести к пагубным последствиям в окружающей среде. Применение различных технологий очистки направлено на нейтрализацию, обезвреживание или утилизацию ценных компонентов. Таким образом, выбор технологии очистки и оборудования зависит в первую очередь от свойств сточных вод и их отклонений от свойств природных вод.

\section{Способы очистки сточных вод золотодобывающих предприятий}

Основными способами очистки промышленных стоков золотодобывающих предприятий от цианидов и тиоцианатов являются:

- физико-химические;

- химические;

- комбинированные;

- биологические.

К физико-химическим способам очистки промышленных стоков от цианидов относятся мембранные (обратный осмос, нанофильтрация и электродиализ), сорбционные методы, процессы с использованием естественного разложения под действием солнечного света замораживания - оттаивания, отгонки.

К химическим методам очистки циансодержащих стоков относятся процессы хлорирования, окисление кислородом с сернистым газом, озоном, пероксидом водорода, ферратами, пероксомоносерной кислотой $\left(\mathrm{H}_{2} \mathrm{SO}_{5}\right)$. Процессы деструкции используются для того, чтобы разъединить тройную связь углерод-азот, разрушая цианид и производя нетоксичные или менее токсичные вещества.

В основе биологического метода лежат биохимические процессы окисления, фильтрования, поглощения, накопления органических и неорганических веществ. Биологические методы позволяют с помощью различных микроорганизмов и высших водных растений значительно снизить концентрацию цианид-ионов (за исключением железа).

Каждый из указанных методов имеет свои достоинства и недостатки. 
Сдерживание промышленного внедрения очистки циансодержащих стоков сорбционными и мембранными методами обусловлено рядом причин, в первую очередь тем, что в обоих случаях в качестве побочных продуктов получаются сточные солевые растворы. Сброс или переработка этих рассолов трудны и дороги, а в некоторых случаях эти солевые растворы могут быть опасны и потребуют особого обращения. Количество отходящих солевых растворов, полученных при ионообмене и обратном осмосе, обычно составляет 5-30 \% от объема переработанных стоков.

Недостатками хлорирования (наиболее распространенного метода химической очистки) являются: использование опасных или небезопасных реагентов с высокой стоимостью; необходимость точного контроля уровня рН для предотвращения образования хлорциана; возможность вторичного загрязнения стоков; отсутствие возможности регенерации цианида и др.

Биологические методы успешно применяются на предприятиях, расположенных в климатической зоне с постоянной плюсовой температурой.

Обезвреживание сточных вод золотодобывающих предприятий перед их сбросом осуществляется на всех объектах, так как содержание цианидов в стоках многократно превышает нормативы ПДК и требования законодательных документов к качеству воды.

Существующие способы очистки организуются по трем возможным вариантам:

1. Деструкция циансодержащих соединений из всего стока, но в этом случае происходят потери реагентов и увеличение передельных затрат.

2. Организация рециркуляции всех или основной части растворов в технологический цикл с выводом на обезвреживание и сброс относительно небольшого потока сточных вод.

3. Организация дополнительной операции регенерации основной части цианидов с возвратом их в технологический цикл, стоки после удаления цианидов направляются на обезвреживание. Этот вариант может рассматриваться и как самостоятельный, и в сочетании с организацией водооборота.

Возврат основной части цианидов в технологический цикл по вариантам 2 и 3 дает положительный экономический эффект как за счет повторного их использования, так и за счет снижения расхода реагентов, необходимых для проведения процесса их деструкции.

В современных технологических схемах золотодобывающих предприятий, как правило, предусматривается рециркуляция растворов (оборотное водоснабжение), что не только обеспечивает возврат цианидов в процесс, но и многократно сокращает объем сточных вод, направляемых на обезвреживание и сброс.

Затраты на внедрение системы рециркуляции цианида оказываются ниже расходов на закупку реагента, а капитальные вложения могут окупиться менее чем за два года. Кроме того, уменьшение объема стоков, направляемых на обезвреживание, позволяет существенно снизить как капитальные, так и эксплуатационные затраты на этом переделе.

Выбор способа, а также схемы обезвреживания сточных вод в целом зависят от ряда факторов: географического положения предприятия; состава жидкой и твердой фаз хвостов, в частности, соотношения форм цианидов в растворе; физического состояния хвостов; сгущаемости и фильтруемости хвостов; наличия опыта и соответствующей инфраструктуры.

$$
-709-
$$




\section{Результаты лабораторных исследований}

\section{по обезвреживанию сточных вод золотодобывающих предприятий}

Сточные воды технологических процессов, в которых в качестве реагентов использовались соли синильной кислоты, как правило, содержат комплекс токсичных веществ: остаточных количеств вводимого реагента, продуктов реакции цианида с рудными сульфидными минералами и частично окисленными серными полупродуктами, в результате чего образуются цианидные комплексы металлов, а также тиоцианаты. Тиоцианат менее токсичен, чем цианид, но более прочен и, следовательно, более устойчив к разрушению.

Анализ литературных данных показал, что весьма перспективным направлением физикохимических методов очистки является обратный осмос, а химических - окисление озоном. Лабораторная проверка этих методов очистки представляла интерес как с научной, так и с практической стороны.

Исследования проводились на модельных пробах циансодержащих растворов, имитирующих реальные стоки (содержание цианидов варьировалось в диапазоне $0,1-1$, роданидов - $0,1-$ 5 г/дм³) .

Эксперименты по очистке циансодержащих растворов методом обратного осмоса выполнялись при температуре $25^{\circ} \mathrm{C}$ на особо плотной мембране марки SW-30-HR с минимальным размером пор, обеспечивающей особо высокую степень очистки от любых ионов. Схема опытной установки представлена на рис. 1. Пробу сточной воды после отстаивания пропускали через нанофильтрационные мембраны NF-1, NF-2, NF-20 и обратноосмотическую мембрану SW30-НR под давлением 25 атм.

Метод обратного осмоса позволяет понизить концентрацию любых солей более чем десятикратно без применения реагентов при $\mathrm{pH}$ 9,6-10,5. Снижение величины $\mathrm{pH}$ до значений 8,6 и менее приводит к значительному увеличению содержания в фильтрате только цианидов.

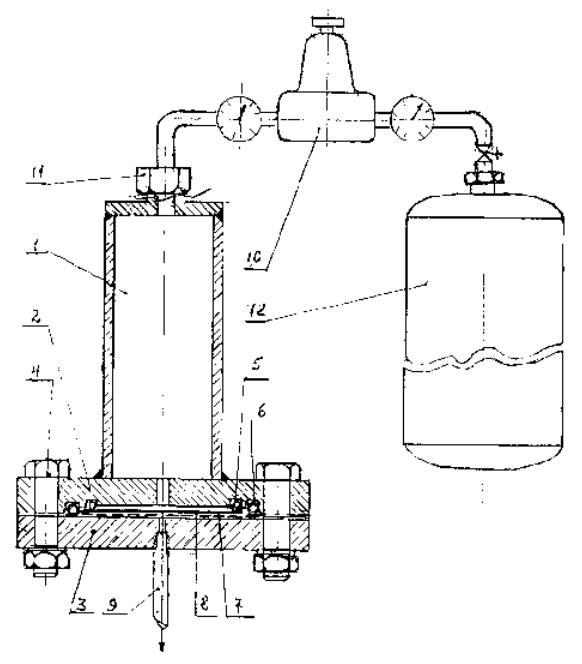

Рис. 1. Схема опытной установки: 1 - емкость фильтруемого раствора; 2 - фланец корпуса; 3 - фланец съемный; 4 - болты с гайками; 5 - уплотнительное кольцо малое; 6 - уплотнительное кольцо большое; 7 - сетка; 8 - мембрана; 9 - выход фильтрата; 10 - редуктор с манометрами; 11 - разъем заполнения раствором и подводка азота; 12 - стандартный баллон сжатого газа

$$
-710-
$$


Результаты экспериментов показывают, что обратноосмотический метод при использовании мембран марки SW-30-HR («морская» мембрана) позволяет создать бессточную и малореагентную технологию очистки циансодержащих стоков. Очищенная от солей вода (фильтрат) может быть использована для промывки хвостов цианирования, а концентрат солей - возвращен на стадию цианирования.

Этот вариант очистки стоков вполне работоспособен при условии, что солевой концентрат не содержит примесей, оказывающих отрицательное влияние на процесс цианирования. К числу таких примесей в первую очередь относятся роданиды.

Роданиды являются значительно более устойчивыми соединениями, чем цианиды. Для окисления роданидов, как показали литературные данные и наши собственные исследования, в основном применяются три метода: автоклавное окисление кислородом, окисление растворами гипохлорита и озонирование.

Процессы, протекающие при окислении роданидов, можно представить в следующем виде:

- окисление кислородом по реакции

$$
\mathrm{NaSCN}+2 \mathrm{O}_{2}+2 \mathrm{NaOH} \rightarrow \mathrm{Na}_{2} \mathrm{SO}_{4}+\mathrm{NaCNO}+\mathrm{H}_{2} \mathrm{O}
$$

- окисление озоном по реакциям:

$$
\begin{aligned}
& \mathrm{NaSCN}+4 / 3 \mathrm{O}_{3}+\mathrm{H}_{2} \mathrm{O} \rightarrow \mathrm{NaCNO}+\mathrm{H}_{2} \mathrm{SO}_{4}, \\
& 2 \mathrm{NaSCN}+2 \mathrm{O}_{3}+2 \mathrm{H}_{2} \mathrm{O} \rightarrow 2 \mathrm{HCN}+\mathrm{Na}_{2} \mathrm{SO}_{4}+\mathrm{H}_{2} \mathrm{SO}_{4},
\end{aligned}
$$

- окисление гипохлоритом по реакции

$$
\mathrm{NaSCN}+4 \mathrm{NaClO}+2 \mathrm{NaOH} \rightarrow \mathrm{Na}_{2} \mathrm{SO}_{4}+\mathrm{NaCNO}+4 \mathrm{NaCl}+\mathrm{H}_{2} \mathrm{O} .
$$

Гипохлорит широко используется при окислении циансодержащих соединений, но это нецелесообразно, так как он вызывает вторичное загрязнение стоков хлорсодержащими продуктами и не обеспечивает очистку до требуемых нормативов.

\section{Исследование процесса автоклавного окисления циансодержащих соединений}

Эксперименты по исследованию процесса автоклавного окисления циансодержащих соединений (роданидов) выполняли на установке, включающей титановый вертикальный гладкостенный автоклав периодического действия вместимостью 3 дм³, линии подачи и сброса газа, сосуд с раствором-поглотителем (щелочь и гипохлорит), баллоны с кислородом и азотом. Общий вид разобранного автоклава представлен на рис. 2.

Автоклав был оборудован: электромагнитным приводом (скорость перемешивания от 0 до 2800 оборотов в минуту); двухъярусной мешалкой; внешним трубчатым электронагревателем; измерителем-регулятором температуры; манометром; пробоотборником; трубкой для подачи газа под мешалку.

Исследования проводили на модельных пробах циансодержащих растворов, имитирующих реальные стоки. 


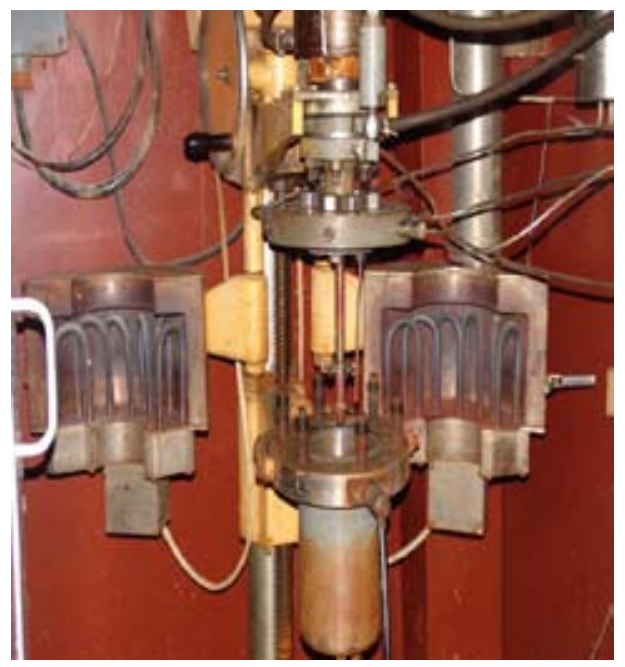

Рис. 2. Внешний вид автоклава

Эксперименты по автоклавному окислению кислородом показали, что, несмотря на высокие параметры проведения процесса: температура 200 - $250{ }^{\circ} \mathrm{C}$, давление 15 - 30 ат; время до 10 ч, - полного разрушения роданидов не достигается.

Степень окисления роданида составила в различных опытах от 47 до $82 \%$. Максимальное окисление было достигнуто при максимальной температуре с применением катализаторов.

Очевидно, что для окисления роданидов необходимы либо более жесткие режимы процесса, что экономически не целесообразно, либо использование более сильных окислителей, например озона.

\section{Исследование процесса озонирования циансодержащих соединений}

Исследования процесса окисления циансодержащих соединений методом озонирования были выполнены на лабораторной установке, включающей озонаторный комплекс (производитель ЗАО «МЭЛП», Санкт-Петербург), реактор, изготовленный из фторопласта, системы подачи, вывода и очистки газа, баллон с кислородом.

Озонаторный комплекс состоит из блока управления, двух блоков синтеза озона (газоразрядного и фотолитического), термокаталитического деструктора озона и газоанализатора, определяющего наличие озона в воздухе рабочей зоны.

Из измерителя концентрации озона озоно-кислородный поток поступает к устройству потребителю озона (фтор пластовый реактор).

Готовая озоно-кислородная смесь направлялась в фторопластовый реактор и далее в термокаталитический деструктор озона, в котором осуществляется конверсия озона в кислород. Из деструктора озона газовый поток, уже не содержащий озона, выбрасывался в атмосферу.

Для обеспечения безопасности работы с озоном в помещении, в котором расположено оборудование озонаторного комплекса, предусмотрен газоанализатор ЭССА, обеспечивающий контроль озона в воздухе. Электрохимический датчик газоанализатора O3-1 располагался в 
зоне наиболее вероятного выброса озона. При превышении предельно допустимой концентрации озона в зоне расположения датчика блок управления запрещает работу блока синтеза озона.

Реактор представлял собой стакан объемом 1 дм³, выточенный из прутка фторопласта с внешней резьбой, по которой накручивается крышка. Крышка реактора имеет отверстия с уплотнительными фланцами, через которые в реактор вводятся: мешалка; сопло для подвода озона; сопло для отвода отходящих газов; стеклянный электрод для измерения $\mathrm{pH}$; электрод для измерения ОВП.

Результаты экспериментов показали, что окисление циансодержащих соединений (роданидов) протекает с высокой скоростью при нормальной температуре и давлении, при отсутствии специальных катализаторов и дополнительных реагентов, а значит, без вторичного загрязнения. Следует отметить, что во всех опытах степень окисления достигала $100 \%$.

Метод озонирования обеспечивает достижение требований законодательства по содержанию цианидов и роданидов в сточных водах. Более низкая себестоимость процесса, связанная с отсутствием реагентов и, соответственно, затрат на их приобретение и доставку к золотодобывающим предприятиям, а также возможность регенерации цианида делают предложенный метод конкурентоспособным.

\section{Основные преимущества применения озона для очистки сточных вод}

- Озон синтезируется из кислорода или из окружающего воздуха.

- Химически озон очень активен, поэтому в процессе очистки реакции происходят очень быстро и не требуют специальных условий, таких как высокие температуры или высокие давления.

- Эффективен озон против всех форм цианидов и способен регенерировать цианиды из роданидов, что может обеспечить многократное снижение эксплуатационных расходов.

- Озон не образует нежелательных побочных токсичных продуктов.

- Процессы озонирования не требуют постоянной покупки, доставки и хранения большого количества реагентов.

\section{Список литературы}

[1] Котляр Ю.А. [и др.]. Металлургия благородных металлов. М.: Руда и металлы, 2005. 432 c. [Kotliar Iu.A. and others. Metallurgy of precious metals. Moscow: Ruda i metalli, 2005. 432 p. (in Russian)].

[2] Арсов Г.В. Применение цианидов в золотодобыче и Международный кодекс использования цианидов (ICMC), Золото и технологии, 2012, № 1(15). [Arsov G.V. The use of cyanide in gold mining and the International Cyanide Management Code. Zoloto i technologii, 2012, № 1(15). (in Russian]. 